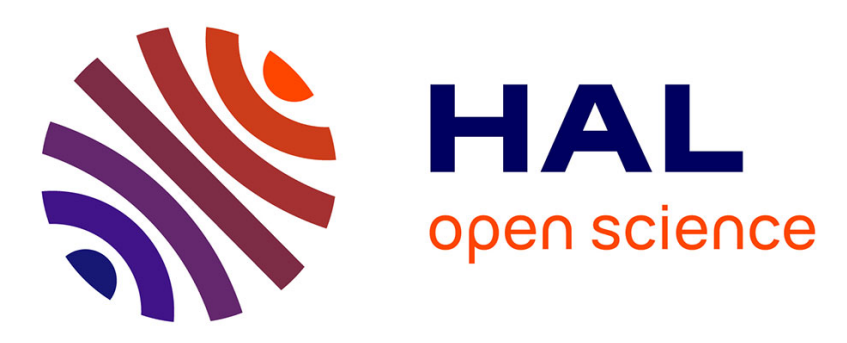

\title{
Neodymium doped SrLaAlO4. A new promising crystal for laser application
}

\author{
W. Ryba-Romanowski, S. Golab, G. Dominiak-Dzik, A. Pajaczkowska, M.
}

Berkowski

\section{- To cite this version:}

W. Ryba-Romanowski, S. Golab, G. Dominiak-Dzik, A. Pajaczkowska, M. Berkowski. Neodymium doped SrLaAlO4. A new promising crystal for laser application. Journal de Physique IV Proceedings, 1994, 04 (C4), pp.C4-561-C4-564. 10.1051/jp4:19944135 . jpa-00252587

\section{HAL Id: jpa-00252587 https://hal.science/jpa-00252587}

Submitted on 1 Jan 1994

HAL is a multi-disciplinary open access archive for the deposit and dissemination of scientific research documents, whether they are published or not. The documents may come from teaching and research institutions in France or abroad, or from public or private research centers.
L'archive ouverte pluridisciplinaire HAL, est destinée au dépôt et à la diffusion de documents scientifiques de niveau recherche, publiés ou non, émanant des établissements d'enseignement et de recherche français ou étrangers, des laboratoires publics ou privés. 


\title{
Neodymium doped $\mathrm{SrLaAlO}_{4}$. A new promising crystal for laser application
}

\author{
W. RYBA-ROMANOWSKI, S. GOŁA̧B, G. DOMINIAK-DZIK, A. PAJACCZKOWSKA* and \\ M. BERKOWSKI**
}

Institute of Low Temperature and Structure Research, Polish Academy of Sciences, Wroclaw, Poland

${ }^{*}$ Institute of Electronic Materials Technology, Warsaw, Poland

${ }^{* *}$ Institute of Physics, Polish Academy of Sciences, Warsaw, Poland

\begin{abstract}
Single crystals of neodymium doped $\mathrm{SrLaAlO}_{4}$ have been grown by the Czochralski method and investigated using the methods of optical spectroscopy. Absorption band centered at $806 \mathrm{~nm}$ is particularly intense in this crystal and this feature seems to be advantageous for side pumping with GaAlAs laser diode bars. Available spectroscopic data indicate that excited states absorption might be of low importance in $\mathrm{SrLaAlO}_{4}: \mathrm{Nd}$.
\end{abstract}

$\mathrm{SrLaAlO}_{4}$ belongs to a wide family of compounds of general formula $\mathrm{ABCO}_{4}$, where $\mathrm{A}=$ $\mathrm{Sr}, \mathrm{Ca} ; \mathrm{B}=\mathrm{Y}, \mathrm{La}-\mathrm{Gd} ; \mathrm{C}=\mathrm{Al}$ or Ga. Single crystals samples of undoped and Nd doped $\mathrm{SrLaAlO}_{4}$ have been grown by the Czochralski method. The growing procedure is extremely difficult since the material tends to form nonstoichiometric compositions displaying various colours associated with absorption of light by structural defects.

At the present stage of development of our growing technique, the crystals produced contain an appreciable amount of colour centres which absorb in the blue region of spectrum.

$X$ - ray investigation showed that the crystals are tetragonal in space group $14 / \mathrm{mmm}$ with lattice constants $\mathrm{a}=3.85 \mathrm{pm}$ and $\mathrm{c}=12.95 \mathrm{pm}$. The crystal structure is built up from translationally equivalent $\mathrm{AlO}_{\sigma}$ layers formed in the ab plane. The aluminum atoms occupy $\mathrm{mmm}\left(\mathrm{D}_{4 h}\right)$ sites and are surrounded by six oxygen atoms. Among them two terminal oxygens are situated in the $\mathrm{C}_{4 v}$ sites and the remaining four in the $\mathrm{D}_{2 h}$ sites. Between the layers the $\mathrm{Sr}$ and $\mathrm{La}$ atoms are randomly distributed in nine-coordinated sites of $\mathrm{C}_{4 v}$ symmetry. Resulting structural disorder broadens strongly the spectral lines associated with electronic transitions of neodymium in the doped compound.

Degree of inhomogeneous broadening of Nd luminescence is high in this matrix. In Fig. 1 


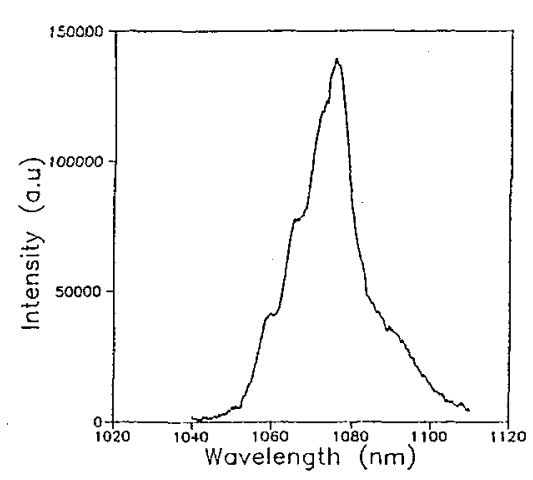

Figure 1. Room temperature I uminescence band associated with the ${ }^{4} \mathrm{~F}_{3 / 2}$ $-{ }^{4} I_{11 / 2}$ transition

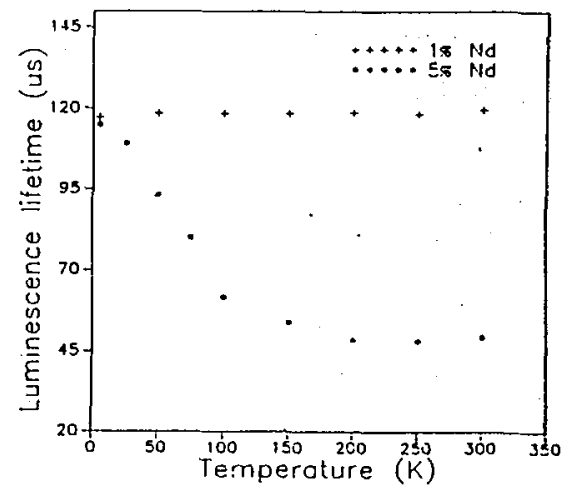

Figure 2. Effect of temperature on luminescence lifetimes for two Nd concentrations.

we present a room temperature luminescence band associated with the ${ }^{4} \mathrm{~F}_{3 / 2}{ }^{-4} \mathrm{I}_{11 / 2}$ transition. Effective bandwidth of this transition is about $22 \mathrm{~nm}$ and may be even higher in nonstoichiometric compositions [1]. Broad luminescence band offers some output wavelength tunability, but reduces the value of stimulated emission cross section. Two samples with different $\mathrm{Nd}$ concentration have been investigated. One of them contained 1 at $\%$ and the other contained 5 at $\%$ of $N d$. Influence of temperature on the ${ }^{4} F_{3 / 2}$ luminescence lifetime is shown in Fig.2. At room temperature the selfquenching of luminescence is important and it will be a limiting factor which should be considered in evaluation of optimal doping level for laser application. At liquid helium temperature the measured lifetimes are essentially the same for both the samples. In Fig. 3 we plotted the rate of selfquenching of Nd luminescence versus temperature for the heavily doped sample. The points in this figure indicate the values obtained by subtracting the inverse values of measured lifetimes for 5 at $\%$ sample from those recorded for 1 at $\%$ sample. Strong increase of luminescence quenching with increasing temperature indicate that the process is phonon assisted or condition of resonance for cross relaxation is fulfilled for higher energy components of the ${ }^{4} I_{9 / 2}$ ground state. In Fig.4 the absorption band corresponding to the ${ }^{4} \mathrm{I}_{9 / 2}-{ }^{4} \mathrm{~F}_{5 / 2},{ }^{2} \mathrm{H}_{9 / 2}$ transition of $\mathrm{Nd}$ in $\mathrm{SrLaAlO}_{4}$ is presented. It should be noted that almost all band intensity is comprised in unusually narrow spectral region from about $800 \mathrm{~nm}$ to $813 \mathrm{~nm}$. As the oscillator strength for this transition in $\mathrm{SrLaAlO}_{4}: \mathrm{Nd}$ is higher than in YAG:Nd, the absorption coefficient in the band maximum is particularly high. The pumping light from GaAlAs laser diode tuned to $806 \mathrm{~nm}$ will be attenuated by two orders of magnitude over only $0.5 \mathrm{~mm}$ of crystal containing 5 at $\%$ of $\mathrm{Nd}$. 


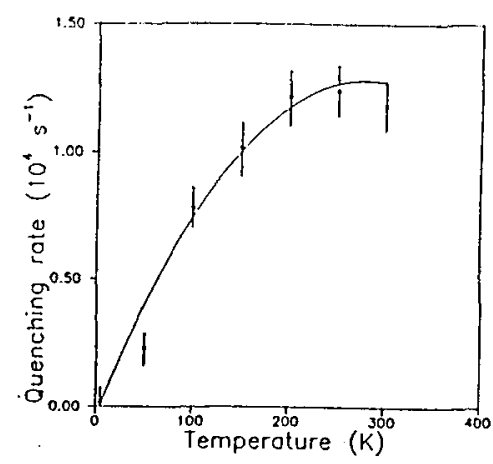

Figure 3.Rate of concentration quenching of $\mathrm{Nd}$ luminescence versus temperature

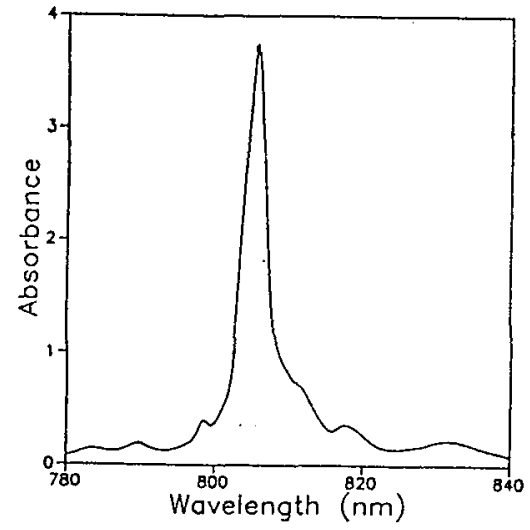

Figure 4. Absorption band corresponding to the ${ }^{4} I_{9 / 2}$ $-{ }^{4} \mathrm{~F}_{5 / 2},{ }^{2} \mathrm{H}_{9 / 2}$ transition.

This feature seems to be particularly advantageous for side pumping with laser diode bars. Like other disordered crystals, $\mathrm{SrLaAlO}_{4}: \mathrm{Nd}$ is expected to be an intermediate gain laser material suited for repetitively pulsed high energy lasers. However, overall efficiency of a diode laser pumped $\mathrm{SrLaAlO}_{4}$ : Nd laser can not be predicted basing on spectroscopic data obtained thus far. Slope efficiencies recorded for lasers employing disordered crystals are lower than that of YAG:Nd. Unsatisfactory performance is attributed to low extraction efficiency [2] or to excited state absorption (ESA) from the metastable ${ }^{4} \mathrm{~F}_{3 / 2}$ level [3].

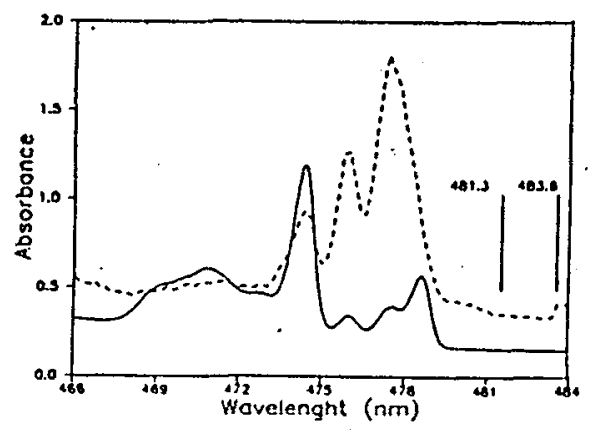

Figure 5.Polarized absor-ption band recorded at $5 \mathrm{~K}$ and corresponding to the ${ }^{4} \mathrm{I}_{9 / 2}(1)$ ${ }^{2}{ }^{G / 2}{ }_{9 / 2}$ transition.
We made an attempt to estimate the importance of the latter process using the results of spectroscopic investigation. In Fig. 5 we present a polarized absorption band recorded at $5 \mathrm{~K}$ and corresponding to the ${ }^{4} \mathrm{I}_{9 / 2}(1)-{ }^{2} \mathrm{G} 1_{9 / 2}$ transition of neodymium. Energies of the crystal field components of the ${ }^{2} \mathrm{G}_{9 / 2}$ state may be easily identified. Two arrows in the figure indicate the wavelengths corresponding to sums of expected laser photon energy (determined from the maximum

of luminescence band shown in Fig.1) and the energies of lower and higher crystal field components of the ${ }^{4} \mathrm{~F}_{3 / 2}$ state. It can be seen that at low temperature the condition of resonance for ESA is not fulfilled. The mismatch is not high however. With increasing 
temperature the energy levels may shift making the energy mismatch higher or lower. The experimental verification of these predictions is now being prepared.

Acknowledgements

This work was supported in part by the Committee for Scientific Research under grants no.8-8035 9203 and no. 3-36419203

\section{References}

[1] W.Ryba-Romanowski, Acta Phys. Polon. in press.

[2] N.Mermilliod, R.Romero, I.Charlier, C.Garapon, R.Moncorgé, IEEE J.Quantum Electron 28, 1179 (1992)

[3] T.Y.Fan and M.Kokta, IEEE J.Quantum Electron. 25, 1845, (1989) 